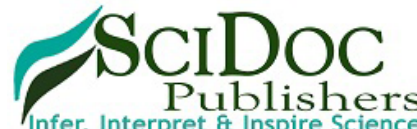

\author{
International Journal of Dentistry and Oral Science (IJDOS) \\ ISSN: 2377-8075
}

\title{
Evaluation And Accuracy Of Digital Radiography And Electronic Apex Locator In Working Length Determination Of Primary Mandibular Second Molars - An In-Vivo Study
}

Research Article

Dr. Sruthi Suguna ${ }^{1}$, Dr. Ganesh Jeevanandan² ${ }^{*}$, Dr.S.Rajeshkumar ${ }^{3}$.

${ }^{1}$ Post Graduate, Saveetha Dental College and Hospitals, Saveetha Institute of Medical and Technical Sciences, Saveetha University, Chennai-77.

${ }^{2}$ Reader, Department of Pediatric and Preventive Dentistry ,Saveetha Dental College and Hospitals, Saveetha Institute of Medical and Technical Sciences, Saveetha University, Chennai-77.

${ }^{3}$ Associate Professor, Department of Pharmacology, Saveetha Dental College and Hospitals, Saveetha Institute of Medical and Technical Sciences, Saveetha University, Chennai-77.

\section{Abstract}

Background: Complete disinfection of root canal is one of the main goals in pulpectomy. However, complete disinfection is only feasible after precise working length. Accurate working length determination, simplicity of the technique, and children cooperation are important aspects in the triumph of endodontic treatment in primary teeth.

Objective: The purpose of the study is to evaluate the accuracy of Electronic Apex Locator (EAL) with the Digital radiographic method for working length determination of root canals in primary mandibular second molars.

Materials and Methods: A randomized clinical trial was conducted on 30 primary mandibular second molars which were indicated for pulpectomy in the patients of the age group of 4-10 years. Endodontic treatment was required due to irreversible pulpitis. Standard endodontic access cavity preparations were done and the actual length was calculated. A standardized radiograph of the tooth was taken using digital method. The working length was determined using EAL and digital radiographic method during pulpectomy procedure

Results: From the results obtained we can conclude that working length determined in primary mandibular second molars using EAL and Digital radiography did not show any significant difference in the mean working length measurements.

Conclusion: EAL is comparable to digital radiography in determining the working length in the primary mandibular second molars. Hence, EAL can be safely used as an alternative to digital radiography in determining working length in primary molars.

Keywords: Apex Locator; Digital Radiography; Primary Teeth; Second Molar; Working Length.

\section{Introduction}

Early childhood is the most crucial momentfor positive intervention. Children's development during this phase is strongly affected by their environment, and that effect continues to impose a strong impact on the rest of their lives. Early Childhood Caries (ECC) continues to be one of the most common chronic diseases globally.It does not only affect children's oral health, but also the general health of children.[1,2] ECC can begin early in life, progresses rapidly in those who are at high risk, and often goes untreated. [3, 4] Its sequel can affect the abiding quality of life of the children and their families. Intervention at the early stage is obligatory to prevent the destruction of the crown and cease the caries from advancing.[5] Pulpectomy is a palliative treatment approach by preventing the premature loss of primary teeth that can result in consequences such as loss of arch length, insufficient space for erupting permanent teeth, impaction of premolars, and mesial tipping of molar teeth close to the lost primary molar. [6, 7] This approach has attained worldwide acceptance over the last few years. The main objective of pulpectomy is to disinfect the root canals thoroughly. However, complete disinfection is only feasible after accurate working length determination of root canal.

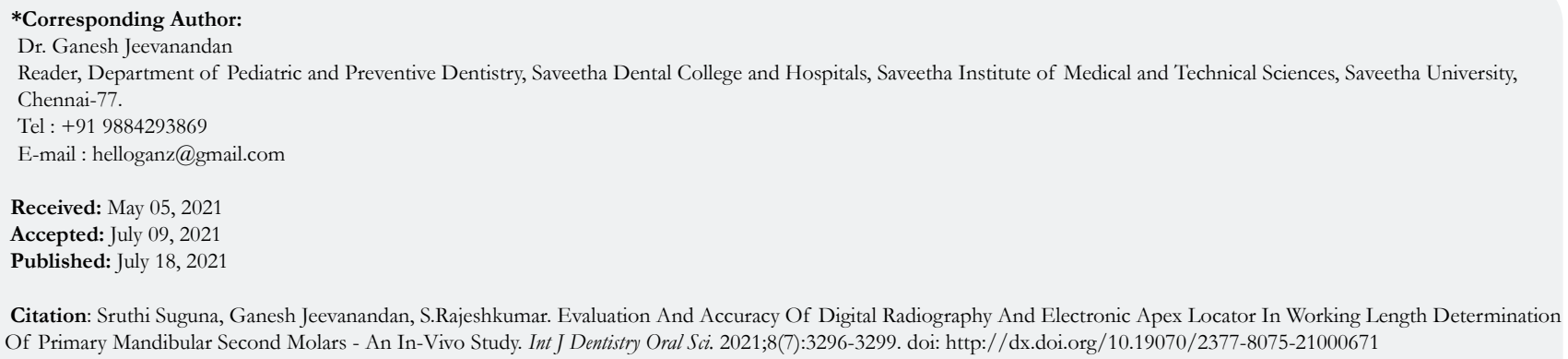

Copyright: Ganesh Jeevanandan ${ }^{\mathcal{O}}$ 2021. This is an open-access article distributed under the terms of the Creative Commons Attribution License, which permits unrestricted use, distribution and reproduction in any medium, provided the original author and source are credited. 
Thus, determining accurate working length is vital for endodontic success.Patient cooperation ismost important while performing pulpectomy; however, it's determined by the procedure and its duration. [8]

The Glossary of endodontic terminology of the American Association of Endodontists describes the working length as "the distance from a coronal reference point to the point at which canal preparation and obturation must terminate".[9] Reference point is the location on the occlusal or incisal surface from which measurements are made.[10] Most frequently used strategies for determination of working length includes tactile sensation, conventional or digital radiography. But, each of these methods has their own obstructions. [11] The tactile perception is simple and most effective procedure, but it was said to be imprecise in root canal systems and the specialist should be knowledgeable, welltrained, well-prepared and have good experience. Drawbacks with radiographic methods comprise distortion of images over position of roots of adjacent structures, two-dimensional view of a three-dimensional image, struggling to identify apical foramen due to resorption.[12-14] Added main limitation with conventional radiography is radiation exposure, requires child cooperation and bulkier/expensive instruments.[15] These drawbacks gave rise toEAL's. They were developed by Suzuki in 1942 and Sundae in 1962. [15,16] They provide the possibilities to lessen patient exposure to ionizing radiation and decrease procedure time both of which adds to the patient cooperation. Nevertheless, accuracy of determination of working length with EALin primary dentition is considered to be limited because of complicated root anatomy and various phases of physiologic resorption. Therefore, the current study was carried out to compare the accuracy of the EAL with the digital radiographic method for working length determination of root canals in primary mandibular second molars.

\section{Materials And Methods}

A randomized clinical trial was executed in the Department of Paediatric and Preventive Dentistry, Saveetha Dental College following the acceptance from the Institutional Review Board from November 2020- January 2021. The formal consent was obtained from the parents of the children who engaged in the study. CONSORT guidelines [17] for planning and reporting clinical trials in paediatric endodontics was followed during different phases of the study [Figure-1]

\section{Sample size estimation and study participant's selection}

The sample size was calculated from a an earlier study with $95 \%$ power, alpha error at 5\%, using G Power analysis and arrived to a total sample of 30 teeth.[18] Cooperative, healthy children between 4 and 10 years of age necessitating pulpectomy in primary mandibular second molars with minimum of two-third of root length present were chosen and were randomly designated to one of the two groups in consonance to the computer generated randomization sequence, where the working length determination was done using and EALin Group 1 and Digital radiography in Group 2. Children with systemic diseases, lacking cooperative ability were eliminated from the study. Also, teeth with calcifications, periapical radiolucency, pathological root resorption and inadequate coronal tooth structure to receive stainless steel crown and existence of extra roots or root canals were excluded from participation in the present study.

\section{Clinical Procedure}

A full mouth observation with X-ray of the teeth designated for pulpectomy was taken ahead to the start of the clinical procedure. Local anaesthesia was administered using lignocaine (LOX* $2 \%$ adrenaline, Neon Laboratories Limited, India). The indicated tooth for pulpectomy was isolated using rubber dam (GDC Marketing, India) for better visibility and to improve the efficiency of the operator. No.6 round bur was used in a high speed hand piece to remove the superficial caries and complete de-roofing of the pulp chamber was done using No.330 pear shaper bur (Mani, Inc, Tochigi, Japan).

Group 1: Thirty teeth were determined using EAL (PropexPixiDentsply) as per manufacturer's recommendation. The 15 size $\mathrm{K}$ file (Mani Co., Japan) was inserted into the root canal till it was able to achieve a snug fit at the root apex as with tactile sensation. Then the buccal clip of the electronic apex locator was applied to the patient's lip corner and measurement was taken. The file was inserted into the root canal and when the apex is reached, a solid tone is emitted. The rubber stopper in the file was then fixed after the display was stable for 5 seconds. The same procedure was repeated for all three root canals (1 mesiobuccal, 1 mesiolingual, and 1 distal) Length of the root canal file was measured using electronic digital caliper (Radium Pvt Ltd. India).

Group 2: The same thirty teeth were determined using digital radiograph using PSP Sensor (Durr Dental, Germany). The image was processed immediately in a PSP scanner (Vistascan Mini Plus, Durr Dental, Germany) to confirm the position of the file tip in the root canal and to see whether it had reached the root canal exit. Radiographs were taken with necessary radiation protection measures and precautions like lead apron and thyroid collar application to the patient. A radiograph was taken at this stage in all three root canals ( 1 mesiobuccal, 1 mesiolingual, and 1 distal) Length of the root canal file was measured using electronic digital caliper (Radium Pvt Ltd. India).

Teeth were then instrumented using Kedo-SG blue paediatric rotary files (Reeganz Dental Care Pvt. Ltd. India) as per manufacturer's recommendation. D1 rotary files were used for canal

Figure 1. 12 Well ELISA plates containing nauplii at different concentration levels of SDF.

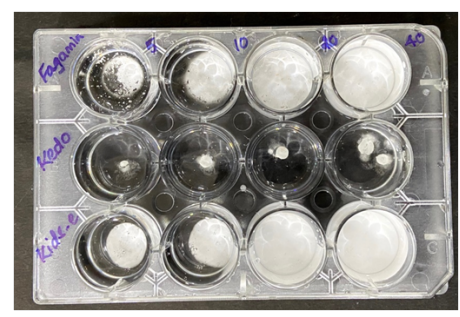


preparation of the mesiobuccal and mesiolingual canals and E1 rotary files were used for distal canal preparation. The rotary files were used with an X-smart endodontic motor (Dentsply India Pvt.Ltd., Delhi, India) at $300 \mathrm{rpm}$ and $2.2 \mathrm{~N} \mathrm{~cm}$ torque. $17 \%$ EDTA gel (RC help, Prime dental products, Pvt. Ltd. India) was used as a lubricating paste to coat the files before instrumentation into the canals. The irrigation solution was standardised to $1 \mathrm{ml}$ of $1 \%$ sodium hypochlorite and $15 \mathrm{ml}$ of saline in all the three groups. The canals were dried using sterile paper points(Adenta). The root canals were obturated using Metapex (Meta Biomed Co. Ltd. Chungbuk, Korea) by gently pushing the material with cotton pellets. The glass ionomer cement was used as the entrance filling and was restored with stainless steel crown on the same appointment. All the clinical procedures were done by a single operator to avoid operatory bias.

\section{Statistical Analysis}

Data was entered in Microsoft Excel spreadsheet and analyzed using SPSS software (version 23). Shapiro-wilk test was used to determine the test of normality of the data set. Descriptive statistics were used for data summarization and presentation. Independent t-test was used to compare the mean difference. The level of significance was set at a value of $\mathrm{P}<0.05$

\section{Results}

A total of 30 children with a mean age of 6.76 years participated in the study [Table-1] The frequency distribution of gender with 17 females (56.67\%) and 13 males (43.33\%) were noted [Table-1; Figure-1] Distribution of mean working length of all three canal values determined using Digital Radiograph and Apex Locator is illustrated in Figure-2, Figure- 3.Table 2 describes the comparison of mean working length for all three canals and it was observed that the readings were closely matched. However, there was no statistical significant difference noted between the two groups $(\mathrm{P}$ $>0.05$, independent t-test)

\section{Discussion}

Evaluating the length of the root canal and accordingly the point at which preparation, disinfection and obturation should terminate is a vital part of endodontic treatment.Even though quite a few ex-vivo researches have been executed to assess the accuracy of working length determination in primary teeth $[19,20]$ accurate simulation of the oral environment is impossible in ex vivo situations and as such cannot be a true representative of clinical conditions in which the complete treatment is done in the mouth. There are many issuedreports on the accuracy of determination of the WL with apex locators in permanent teeth but the details on primary teeth are sparse. Hardly few studies have been carried outsolely in in-vivo conditions in the primary teeth. $[18,21]$ In the current study, an effort was made to reproduce what occurs during a routine endodontic treatment. To the best of our knowledge, no in vivo study has been done to evaluate the accuracy of EAL and digital radiography in working length determination in primary mandibular second molars.

The use of apex locator has acquired greater acceptance over the last few years to avoid the risk of radiation, technical and processing errors. [22] A fifth generation apex locator introduced by Dentsply called the Propex Pixi was used in the current study. The indication 0.0 on the Propex Pixi screen relates to the minor apical foramen file position and the manufacturer recommends working $0.5 \mathrm{~mm}$ short of the zero reading. In the present study, working length estimation by the EAL in all the three canals of primary mandibular second molars was comparable to digital radiographic method and the independent $\mathrm{t}$ - test showed statistically insignifi-
Figure 2. Cytotoxicity of Kedo-SDF after 24 hours.

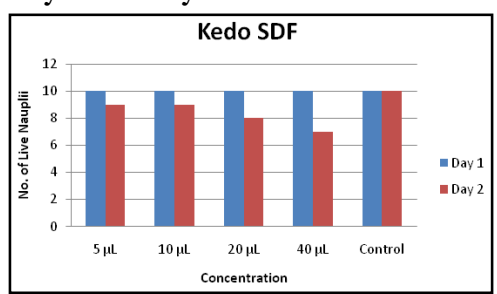

Figure 3. Cytotoxicity of Kidz-e SDF after 24 hours.

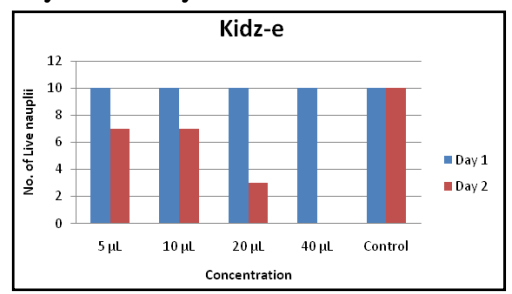

Table.1: Cytotoxicity of three different SDF's.

\begin{tabular}{|c|c|c|c|c|}
\hline \multirow{2}{*}{$\begin{array}{c}\text { Concentra- } \\
\text { tion }\end{array}$} & \multicolumn{4}{|c|}{ Viable Nauplii } \\
\cline { 2 - 5 } & Control & Kedo & Kidz-e & Fagamin \\
\hline $5 \mu \mathrm{L}$ & 10 & 9 & 7 & 9 \\
\hline $10 \mu \mathrm{L}$ & 10 & 9 & 7 & 3 \\
\hline $20 \mu \mathrm{L}$ & 10 & 8 & 3 & 1 \\
\hline $40 \mu \mathrm{L}$ & 10 & 7 & 0 & 0 \\
\hline
\end{tabular}

Figure 4. Cytotoxicity of Fagamin after 24 hours.

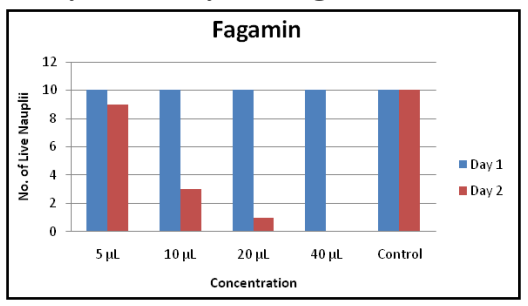


cant difference which is in accordance with the literature. [23, 24$]$ In our study, 4-10 years of age group was taken into account as the teeth at this age have more radiographically visible canals and show no signs of root resorption. Beyond this age group initiation of physiologic root resorption commences. In a former study managed by KM Nanda Kishor, significant difference was found between the radiographic and electronic root canal working length determination. [25] Research done by Muthu Shanmugaraj et al revealedthat the electronic apex locator was a superior method of working length estimation. [26] Musab Hamed Saeed have concluded that digital radiography were more precise, and a definitive method for determining the working length. [27]

Nevertheless, even with the accessibility of all these methods and results from several studies, it still remains a dilemma to merely depend on one method to precisely evaluate the working length. To sum it all up, the radiographic method to establish the working length has been in use since ancient times because of its obvious supremacy mentioned earlier. But, at present with the emergence of advanced technology transforming the Endodontic practice, the Digital radiography \&EALcan be used as an adjunct to the traditional radiographic techniques for working length estimation.

\section{Conclusion}

No statistically significant differences were observed between the measurements obtained using the EAL and the digital radiographic method. Thus, it was possible to conclude that both the techniques are considered safe and accurate methods in primary molars.

\section{References}

[1]. Naidu R, Nunn J, Donnelly-Swift E. Oral health-related quality of life and early childhood caries among preschool children in Trinidad. BMC Oral Health. 2016 Dec 7;16(1):128.Pubmed PMID: 27923355.

[2]. Filstrup SL, Briskie D, da Fonseca M, Lawrence L, Wandera A, Inglehart MR. Early childhood caries and quality of life: child and parent perspectives. Pediatr Dent. 2003 Sep-Oct;25(5):431-40.Pubmed PMID: 14649606.

[3]. Grindefjord M, Dahllöf G, Modeer T. Caries development in children from 2.5 to 3.5 years of age: a longitudinal study. Caries Res. 1995;29(6):449-54.

[4]. Weinstein P, Domoto P, Koday M, Leroux B. Results of a promising open trial to prevent baby bottle tooth decay: a fluoride varnish study. ASDC J Dent Child. 1994 Sep-Dec;61(5-6):338-41.Pubmed PMID: 7897002.

[5]. Msefer S. Importance of early diagnosis of Early Childhood Caries. JODQ. 2006:1-24.

[6]. Dummett CO Jr, Kopel HM. Pediatricendodontics. In: Ingle JI, Bakland LK, editors. Endodontics. 5 th ed. Hamilton: BC Decker Inc.; 2002. p. $861-902$
[7]. Berk H, Krakow AA. A comparison of the management of pulpal pathosis in deciduous and permanent teeth. Oral Surg Oral Med Oral Pathol. 1972 Dec;34(6):944-55.Pubmed PMID: 4565581.

[8]. Bodur H, Odabaş M, Tulunoğlu Ö, Tinaz AC. Accuracy of two different apex locators in primary teeth with and without root resorption. Clin Oral Investig. 2008 Jun;12(2):137-41.

[9]. Ding J, Gutmann JL, Fan B, Lu Y, Chen H. Investigation of apex locators and related morphological factors. J Endod. 2010 Aug;36(8):1399-403.Pubmed PMID: 20647105.

[10]. Mull JP, Manjunath V, Manjunath MK. Comparison of accuracy of two electronic apex locators in the presence of various irrigants: An in vitro study. J. Conserv. Dent. 2012 Apr;15(2):178-182.

[11]. Goldberg F, De Silvio AC, Manfré S, Nastri N. In vitro measurement accuracy of an electronic apex locator in teeth with simulated apical root resorption. J Endod. 2002 Jun 1;28(6):461-3.

[12]. Miano N, Da Silva CA. Lengths and distortion in root canal measurements of upper premolars and upper and lower molars. RGO. $1988 \mathrm{Mar}$ 1;36(2):97-8.

[13]. Plotino G, Grande NM, Brigante L, Lesti B, Somma F. Ex vivo accuracy of three electronic apex locators: Root ZX, Elements Diagnostic Unit and Apex Locator and ProPex. IntEndod J. 2006 May;39(5):408-14.

[14]. Horner K, Shearer AC, Walker A, Wilson NH. Radiovisiography: an initial evaluation. Br Dent J. 1990 Mar;168(6):244-8.

[15]. Suzuki K. Experimental study on iontophorosis. J JpnStomatol. 1942;16:411-429.

[16]. Sunada I. New method for measuring the length of the root canal. J. Dent. Res. 1962 Mar;41(2):375-87.

[17]. Altman DG, Schulz KF, Moher D, Egger M, Davidoff F, Elbourne D, et al. The revised CONSORT statement for reporting randomized trials: explanation and elaboration. Ann Intern Med. 2001 Apr 17;134(8):663-94.

[18]. Neena IE, Ananthraj A, Praveen P, Karthik V, Rani P. Comparison of digital radiography and apex locator with the conventional method in root length determination of primary teeth. J Indian SocPedodPrev Dent. 2011 Oct $1 ; 29(4): 300$.

[19]. Gordon MP, Chandler NP. Electronic apex locators IntEndod J. 2004 Jul;37(7):425-37.

[20]. Ahmad IA, Pan SC. Accuracy of electronic apex locators in primary teeth: A meta-analysis. IntEndod J. 2014:1-10.

[21]. Oznurhan F, Unal M, Kapdan A, Ozturk C, Aksoy S. Clinical evaluation of apex locator and radiography in primary teeth. Int J Paediatr Dent 2014:1-4.

[22]. Kim E, Lee SJ. Electronic apex locator. Dent Clin North Am. 2004 Jan $1 ; 48(1): 35-54$

[23]. Melius B, Jiang J, Zhu Q. Measurement of the distance between the minor foramen and the anatomic apex by digital and conventional radiography. J Endod. 2002 Feb;28(2):125-6.Pubmed PMID: 11833685.

[24]. Burger CL, Mork TO, Hutter JW, Nicoll B. Direct digital radiography versus conventional radiography for estimation of canal length in curved canals. J Endod. 1999 Apr 1;25(4):260-3.

[25]. Kishor KM. Comparison of working length determination using apex locator, conventional radiography and radiovisiography: an in vitro study. J Contemp Dent Pract. 2012 Jul 1;13(4):550-3.Pubmed PMID: 23151708.

[26]. Shanmugaraj M, Nivedha R, Mathan R, Balagopal S. Evaluation of working length determination methods: an in vivo / ex vivo study. Indian J Dent Res. 2007 Apr-Jun;18(2):60-2.Pubmed PMID: 17502709.

[27]. Saeed MH, Luke AM, Abtahl NA, Pradeep P. An in vitro comparison of root canal measurement in permanent teeth by electronic apex locator, conventional and digital radiography. World J. Dent. 2011 Oct;2(4):312-5. 